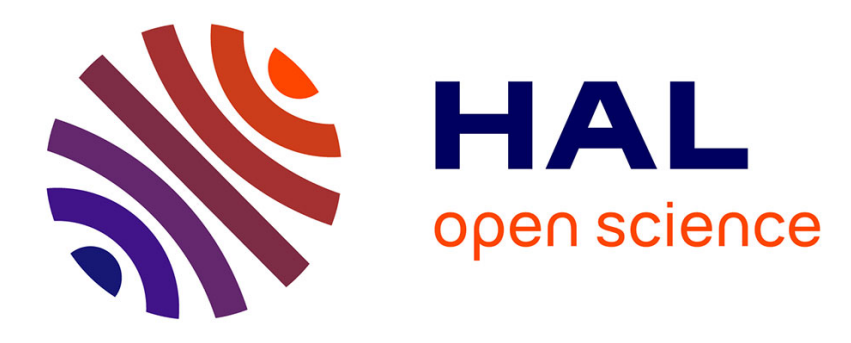

\title{
A Mulimodeling Framework for Complex Learning Activity Designs \\ Sofiane Aouag
}

\section{To cite this version:}

Sofiane Aouag. A Mulimodeling Framework for Complex Learning Activity Designs. International Conference on Web-Based Learning 2008, Aug 2008, China. edutice-00425148

HAL Id: edutice-00425148

https://edutice.archives-ouvertes.fr/edutice-00425148

Submitted on 1 Dec 2009

HAL is a multi-disciplinary open access archive for the deposit and dissemination of scientific research documents, whether they are published or not. The documents may come from teaching and research institutions in France or abroad, or from public or private research centers.
L'archive ouverte pluridisciplinaire HAL, est destinée au dépôt et à la diffusion de documents scientifiques de niveau recherche, publiés ou non, émanant des établissements d'enseignement et de recherche français ou étrangers, des laboratoires publics ou privés. 


\title{
A Mulimodeling Framework for Complex Learning Activity Designs
}

\author{
Sofiane Aouag \\ LRL, \\ Maison de la recherche, 4 rue Ledrue \\ 63057 Clermont-ferrand, France \\ aouag@lrl.univ-bpclermont.fr
}

\begin{abstract}
This paper proposes a modeling framework for learning activities centered on the design of their components (pedagogical instruments). The learning activity is represented as learning object where the structural components are the reusable objects representing the pedagogical instruments. This purpose presents a new current of learning activity design based on activity theory where its design means the specification of its specific teaching materials called pedagogical instruments, this material has the mediation role between the learner and the objects presented in the activity. The outcome of the presented project should be the convergence of cognitive, didactic, interface and content designs.
\end{abstract}

Keywords: Learning activity, learning object, individualizing learning, learning to read, Multimodeling.

\section{Introduction}

The Current research in teaching engineering [10],[15] aims at concentrating on the learner's activity and bringing the learner to the center of research. We propose a new formalism for didactic activity representation by using the approach "learning object" where a lot of recent work has concentrated on aiming at the standardization of their indexing. The goal has been to define open technical standards for computer supported learning environments and education products. Learning objects are elements of a new type of computer-based instruction grounded in the object-oriented paradigm stemming from computer science [15]. We postulate in this paper that the design of the learning activity means the definition of its specific teaching materials called pedagogical instruments; these material has the role of a mediator between the learner and the objects presented in the activity. This paper contains in first the theoretical or conceptual foundations for our work, which falls under what is called activity theory. In the second part we develop the idea based on the multimodelling approach of the learning activity where we announce that the design of the learning activity needs to specify four models: didactic model, knowledge object model, interface model and the cognitive model. Each model comprises the sub models of the pedagogical instruments constituting the learning activity; in the final section we show how we can connect between the different models. Initially, the context of the project and its objectives will be briefly described. 


\section{Context of Work}

Our work is within an interactive learning-to-read environment with a multi-agent architecture 'AMICAL' which has the support of a pluridisciplinary team of professor in primary school (experts of domain), linguist, psychologist, knowledge engineer, data processing specialist. It's a theoretical and development project of a multi-agents and knowledge-based computer for teaching and learning of reading. This project aims to the realization of multimedia intelligent tools likely to contribute the individualization of learning; it is related to the mother tongue (French) and addressed to children in normal schooling on their preparatory course. The system is composed of three types of functional modules: the resource module, the exploration module and the tutorial module. The tutorial module, must lead, in a controlled way to the acquisition of knowledge by the student, to propose session of work. The sessions are the result of a process, "didactic planning", in which the system determines first an objective constructed from the knowledge it has about the student and the knowledge about the domain [3]. Then, the system determines a sequence of didactic activities with correspond to this objective. It is to be noted that the environment of tutoring module adheres to the current paradigm of multi-agent systems, which offer a good way to model a system to help define the actors, their functions and roles, and also their interactions as a society of agents.

\section{Basic Principles of the Framework Methodology}

The pedagogical instrument is a complex artificial object that must undertake the design and the evaluation as a didactic artifact suited to bring into play the learner's knowledge. The basic theory of this proposition is the activity theory [14]. The originality of the mediation concept is the Activity theory, which reflects that human action is mediated by tools and signs [7]. The main problem is to know how learners conduct activity in computer mediated learning environment and how they interact with content using mediating artifacts (pedagogical instrument). All the higher psychological processes are mediated through a tool. One of the most important psychological tools is language, which serves as the "prime device for rendering the world intelligible and for communicating our intentions to others" [13]. So the design of the learning activity means the specification of the nature of this mediation by the design of different layers (didactic, cognitive, knowledge objects and interface).

Rob Koper of Open University of the Netherlands proposes to describe the learning activity using a first version of the language EML, Educational Modelling Language. The specification IMS Learning Design, largely inspired by Rob Koper proposition, provides a modelling conceptual framework in which the scenario of the unit of training is represented throw a theatrical metaphor. A unit of learning is an abstract term used to refer to any delimited piece of education or training, such as a course, a module, a lesson, etc. It can be modelled as an IMS Content Package where the organization part is replaced by an IMS Learning Design. In our point of view the learning activity scenario will be specified by dynamic process that can be called the scenarisation of learning object. This later is characterized, first of all, by knowledge brought into play for learning. Reusability, adaptation, and composition mechanisms are, 
therefore, employed to structure knowledge contents. These knowledge contents are represented in the form of entities < action, knowledge unit $>$ or <action; statute-oflearner's-knowledge; knowledge unit $>$ such a knowledge units are regarded as parameters of individualization of the contents of learning activity and the proprieties of knowledge object (fig.1). The instantiation of these parameters represents the first stage for the scenarisation of the learning object. The basic idea is that the learning objects would be staged, (Instantiation of the content, preparing the list of the instrument to be used and finally specifying the scenario of each pedagogical instrument), a process referred to as 'scenarisation'. Our proposal lies in the use of the rational agent, which individualizes its parameters according to the student model and using three types of rules (didactic rule related to the learning domain, pedagogical rules concerned by the general teaching rules independently of learning to read domain and finally linguistic rules)

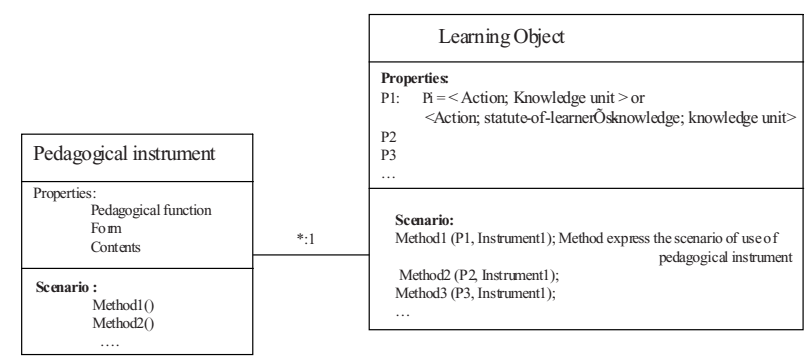

Fig. 1. Learning object meta model according to the UML Class model

\section{Multimodeling of the Learning Activity}

The multimodeling of the learning activity means specifying four models of each activity: The didactic model, the knowledge object model, the interface model and the cognitive model to be detailed by the actors of design. The learning activity design means the specification of the detailed submodels of each pedagogical instrument.

\subsection{Pedagogical Model}

There is no consensus on how to proceed and to describe a pedagogical model. However, today we know that teaching and learning approaches have been motivated by more diverse approaches based on the analysing of learning and teaching strategies that include the manner and the content of the pedagogical material to be presented and used within a wider teaching enterprise. Due to the number of input variables and pedagogical rules, we distinguish between two kinds of models: the general pedagogical model of the system and sub-models associated to each pedagogical instrument (fig.2).

The consideration of pedagogical models thus guides the overall design of the entities to be used by the system. The entities manipulated in the pedagogical model have progressive degree of smoothness (macro, meso and micro scale); the entities 


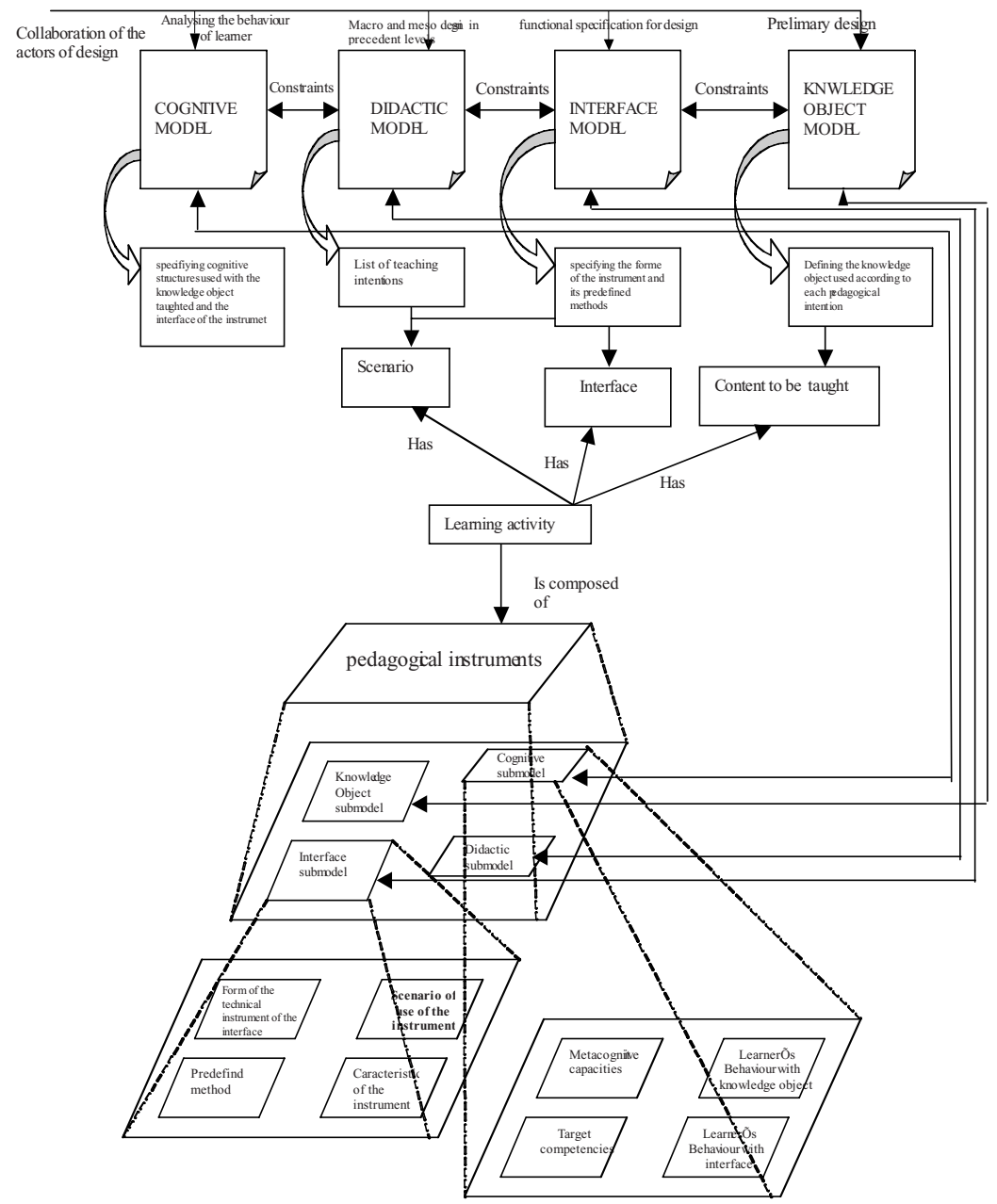

Fig. 2. Multimodeling of the learning activity

presented in macro scale are the objective units, in the meso scale we use the didactic situation type which corresponds to a certain class of didactic situation. The entities represented in the micro scale are the individualizing elements of the instantiated didactic situation which is considered as a multimedia learning object.

The parameters of the instance of the learning object can be used to individualize the object depending on the learner's model and individualizing constraints e.g. "choice of the topic of the text, choice of words, limitation or not of time, help (natural, moment and frequency of the use of help)". These parameters are incorporated in the models specifying the learning activity. The entities manipulated in this model are calculated in the preceding levels, these entities are the objective units represented in the form of couples of information: <action; knowledge unit>; or triplets : <action; 
statute of learner's knowledge; knowledge unit $>$. The objective units represent the properties part of the learning object (Fig 1). For example, the following are valid information couples < Make acquire; sentence limits > or, < verify; Known; word > By instantiating parameters of the contents Words will be instantiated. These couples and triplets are used to report the progress in the state of the learner's knowledge of reading, but with the assumption that this takes into account the different pedagogical factors and policies used within a learning theory (e.g. constructivist). Therefore this model is defined to provide to our system the possibility to adapt the pedagogical behaviour to a specific student. From this optic, the choice of pedagogical actions with respect to learning strategies will be more adaptive (Table.1).

\subsection{Knowledge Object Model}

Merrill and his colleagues in the ID2 Research Group proposed a knowledge representation scheme consisting of knowledge components arranged into knowledge objects [8]. This knowledge object framework is the same for a wide variety of different topics within a subject matter domain, or for knowledge in different subject matter domains. Knowledge object of "learning to read domain" are letters, words, sentences and texts; the micro-component of a knowledge object sentences are the components of words (letters). It would be necessary to characterize the differences between knowledge object as entity and its proprieties, for example: The knowledge objects sentences have 2 types of knowledge:

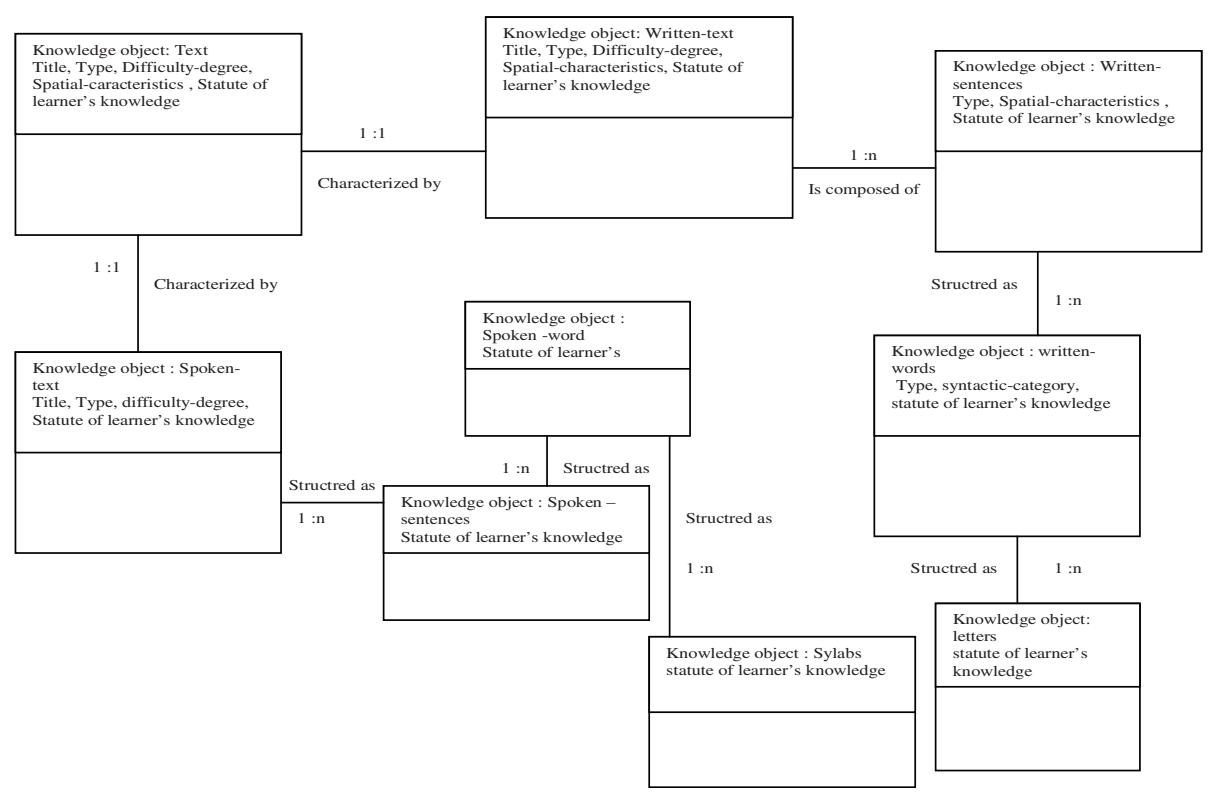

Fig. 3. Learning object model 
- Knowledge associated with properties of the object "sentence" as theoretical space for example: "The association between written/spoken sentences": association grapheme/phoneme, the noun indicates letters, the grapheme representing the word, Structure of word, syntactic categories, the relation between the verbs and the subject, the correspondence written/spoken words. These objects are highlighted systematically each time that a written sentence, is spoken out.

- Knowledge associated with an entity as a semantic unit, which requires the knowledge of the learner about the property of this object(conceptual representation of the sentences).

The text is the most complex knowledge object related to the learning to read domain, it is related to a complex work to be realized by the learner during the reading process. These processes are concerned with a syntactic analysis of sequences of identified words and the development of its cognitive skills by the combination and integration of the significance proposals starting from various indices (morphological, morpho-syntactic and pragmatic). The knowledge object model is represented as Uml class diagram (fig 3).

\subsection{Interface Model}

The interfacing of the didactic activity relates to the adaptation of pedagogical instruments to be used for turning on actions of the system illustrated in the properties of the learning object (fig 1). An example of a pedagogical instrument is "the text field" that can be considered as a support of the text. The pedagogical instrument is characterized by five criteria:

- Pedagogical Function: it corresponds to pedagogical intentions represented as: < action, knowledge unit $>$ or <Action; statute-of-learner's-knowledge; knowledge unit>.

- Scenario of use: the life cycle, number of tests and imposed or proposed help...

- Form: the shape of the instrument (Button defines; Fields of text; Word; letter, an image, colors, dimensions space...)

- Content: (the text, the word, the contents of button...)

- Effects of the instrument: it concerns the learner's way of use of the instrument (its logic of use and the effects on the progress of his knowledge and cognitive states).

We distinguish between the model of use of the interface which is a sub-model of the cognitive model and the interface model. The model of use of the interface can be considered as a set of functions, that allow communication and finalizes the form by which the system transmits information. This model is in coupled with the pedagogical, cognitive and knowledge object models. It transforms the internal representation of the system into comprehensible information for the learner. This model can transmit the same knowledge more or less clearly. Indeed, even when the pedagogical model decides the pedagogical function and contents, the interface model deals with a suitable pedagogical instrument to be used in order to propose the final form to the learner taking into account his learning style and preferences. The most popular technologies are Hiding for adaptive navigation support. 


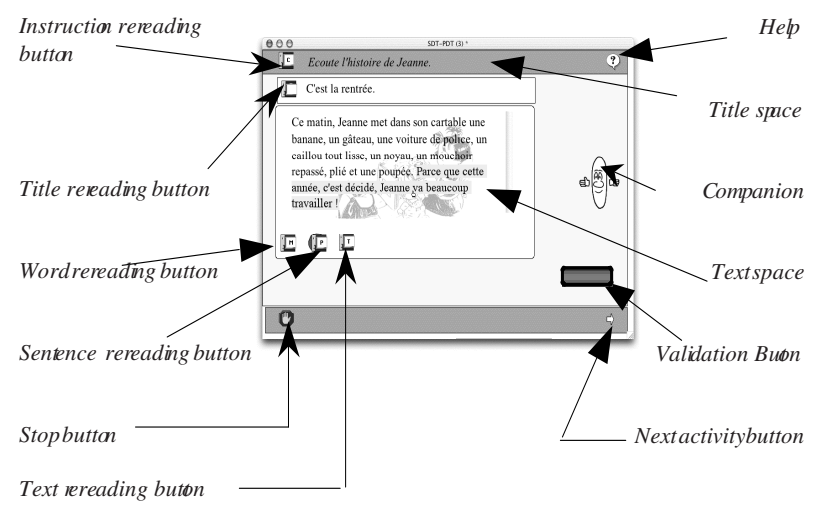

Fig. 4. Tehnical instruments of the interface

The idea of navigation support by hiding is to restrict the navigation space by hiding links to irrelevant pages [2] or to material which the user is not yet prepared to understand. For example if we can detect starting from the behavior of the learner that she/he has an impulsive character (we must hide the "Next" button until the finish of the tasks proposed by the system). The other type of learner can be called "reflexive learner" according to researchers of psychological variables of the functionality of human minds [4], [5]. The Swassing-Barbe Perceptual Modality Instrument has been developed by [1] to identify different learning styles visual, auditory and Kinesthetic. It is significant to understand the basic underpinnings of how individuals learn and retain knowledge. We learn using a combination of Visual Stimuli, Auditory Stimuli and Kinaesthetic Stimuli. The visual style is characterised by the effectiveness of learner's memory in using the vision, the auditory style is related to auditory and the Kinaesthetic style concerned by all what we touch (this stimuli is concerned with pronunciation in the learning to read domain). The pedagogical instrument is the tool that activates these stimuli and allows the learner to maximize its capacities to learn.

Thus, elements of the individualization are considered as variables associated to the instruments (The visualization attribute of the button next which is considered in our case as a decision variable used by the agent). Others types of parameters can be used to individualize the scenario of use of the instrument. The different ways of the use of the instrument can be considered as methods through the object-oriented paradigm. For example if we have a text field in the didactic situation (presentation of the text) the different ways of presenting this text are the possible scenarios of use of this instrument (reading-Word-by-word; sentence-by-sentences and global reading of the text).

\subsection{Cognitive Model}

Many Cognitive psychologists have proposed a diversity of theories of how knowledge is represented in memory [15]. Schema theory postulates that learners represent knowledge in memory as some form of cognitive structure. A knowledge structure 
has a form of a schema representing the information that is required by a learner to be able to solve complex problems. If the required information (knowledge components) and the relationships among these knowledge components are incomplete, then the learner will not be able to efficiently and effectively solve problems requiring this knowledge [8]. So solving a problem requires the learner to not only have the appropriate knowledge representation (schema or knowledge structure) but he or she must also have algorithms or heuristics for manipulating these knowledge components in order to solve problems [15]. The processes of activation of a cognitive process for learner could be defined as a complex knowledge based on the other knowledge to acquire and the cognitive structure implemented at the time of learning. The use of this schema requires a high level of treatment by learner: : to understand, to pridect, to reason, to judge, to interpret, to criticize, to determine the main idea, to summarize, to re-read and self-monitoring, to make connections between their reading and what they already know, and to identify what they need to know about a topic before reading about it; prefixes, and suffixes of words for comprehension; and to use information from their reading to increase vocabulary and enhance language usage [6].

All these knowledge must appear in the cognitive model specified by the congnitien. So the pedagogical instrument is designed to be able to conduit of the learner's strategies (metacognition within the constructivism approach). An example of this conduit is to let the learner identifying word by using syntactic analysis of sequences of words to be identified ( without ambiguous syntactic structures); the second stage is to let him/here acquires the development of the syntactic structure of the various components starting from various indices (morphological, morpho-syntactic, sets of themes and pragmatic) and finaly is to establish the coherence between the proposals inference starting from its knowledge bases stored in memory. he cognitive model contain all process that used by learner to manipulate the interface and to learn for example : Use logic of reading : (left to right ; high-low), apply logic of corresponding : (spoken word/ written word, spoken sentence/written sentences). More generally, this model takes care of communications between the student and the system remainder. The cognitive model contains all process that used by learner to manipulate the interface and to learn for example: Use logic of reading : (left to right ; highlow), apply logic of corresponding : (spoken word/ written word, spoken sentence/written sentences), make use of logic of the use of the interface, make use of pre-required knowledge, apply inference to understand the text, utilize strategies, Bring into play emotional situation. More generally, this model takes care of communications between the student and the system remainder. In reality the use of the instrument is interpreted by a logic implemented by learner within instrumentation process (in the sense of Rabardel [11])

\section{Dynamism of the Learning Activity}

The individualizing learning problem has complex nature due to the tacit knowledge having complex epistemic statutes. These knowledge-based analysis tasks are increasingly complex. The relational model of the learning object represents the dynamic of 


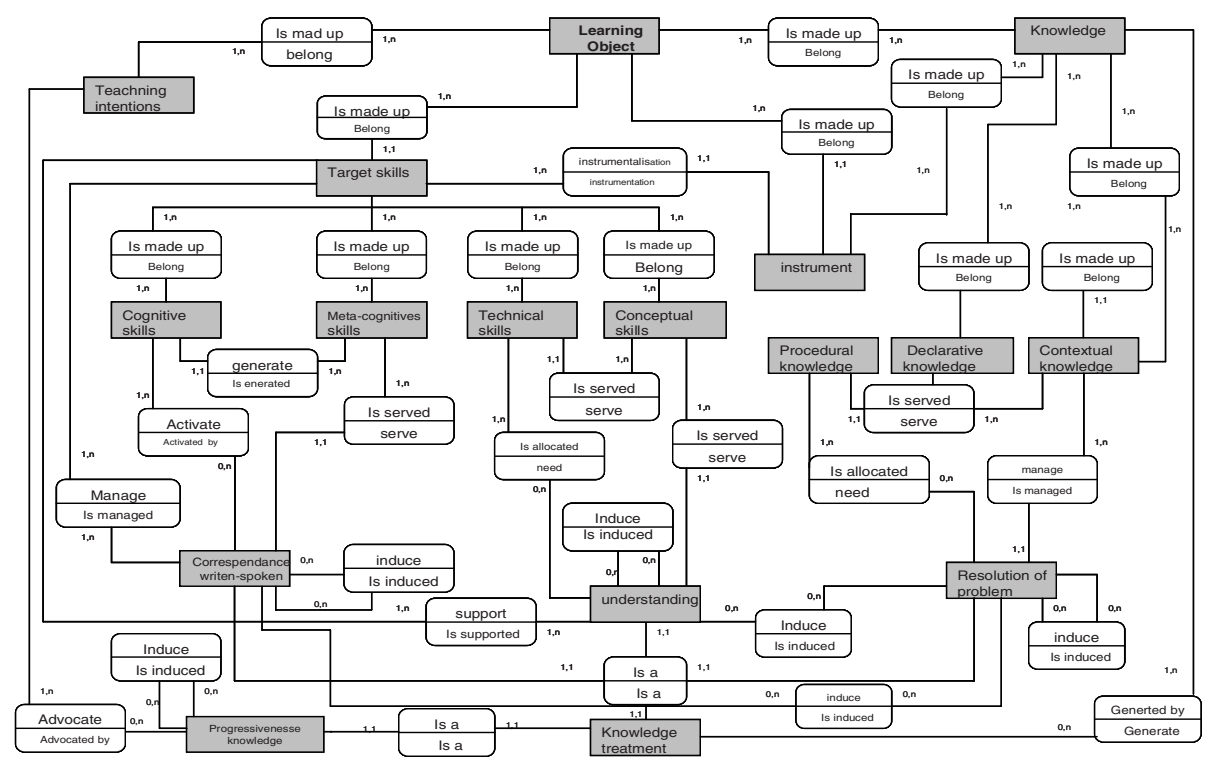

Fig. 5. Relational model for learning object

the learning activity. In the figure below, the activity is made up of four entities (Instrument, Knowledge, target Skills and teaching intentions). The entity 'Instrument' is related with the entity (target skills) by the relation (instrumentation/instrumentalisation), the instrumentalisation is related to four variations of the instrument (content to be taught, interface, mode and moment of intervention), so the enrichment of the instrument by these variations alter the specific teaching material more adaptive through the advocates teaching intentions. The variation of the mode and the moment of intervention of the instrument can let the learner decide to use its meta-cognitive skills (let the learner request the help (instrumentation process)). The system can disable certain kinds of instrument (Instrument-state.disable) to be activated by the learner (for example: listening consign), that make the learner more autonomous and develop its cognitive skills. The moment of intervention of the instrument during the activity of training provides the learner with more time to identify all what is needed to solve the problem. There are three types of knowledge (declarative, procedural and contextual knowledge), the internal relation between these type of knowledge serve as tools used to clarify the resolution of the problem by the learner (activating instrument, using method applied into the instruments ...). The entity 'Progressiveness of knowledge' rest so difficult to be clarified but we can accept the assumption that it has direct relation with teaching intentions defined by the expert of domain and the learning model used by the system.

\section{Connection between Models}

Regardless of the learning activities tools used, once the total design is sufficiently advanced, work can start on the design of individualizing the process of learning 
materials, pedagogical instruments, by connecting different models. We will show in this section how we can use the different models to make decisions in the system. Pattern of edges in the knowledge object graph represents the qualitative dependencies between the variables used to individualize the content of the learning activity (presentation of text). Each knowledge content has possible statutes in the student's model: known, un-known, recognized and possible context where the student has constructed this statute or modified its value. The student's strategy required to do tasks proposed by the system according to the criterion described by the instructional designer in the pedagogical action (Table1). Quite often criteria are referred to as objectives of the agent, such a set of objectives is typically modified during model analysis. In other words, it is easy to determine separately for each criteria, which solution (text represented in the forme of Vector X) is the best one, such as the narrative text competing with the minimization of degree of difficulty to learning more. If the text is preferred by the learner that signifies it fits the motivational criterion, consequently the solution is to propose the preferred topic of text. But the system will not propose only one topic of text, for that another criterion associated with the progressiveness of the system tasks is required, accordingly a preference approach based on methods is used actually in decision theory [12] to specify the criteria. We consider that there are four criteria to be used for making this decision: - progressiveness of tasks system criteria; -motivational criteria (respecting its preferences); - progressiveness of learner's cognitive state and - progressiveness of learner's knowledge criteria.

Let us illustrate this by specifying the decision variables of our illustrative models. In the knowledge object model (Text model) we can find the vector: T( Tilte , Type, difficulty-degree, spatial-characteristic, number-of-time-of-reading); the type of text can be related to the narrative text, dialogue text, descriptive text... In the pedagogical model the decision variables are the variables associated with each type of text, for example the pedagogical intention: (present text : narrative text ; statute : new). The

Table 1. Relationship between learning and teaching strategies in 'autonomous recognition of Words' activity

\begin{tabular}{|c|c|c|}
\hline Learning strategy & Related teaching strategy & Parameters \\
\hline $\begin{array}{l}\text { St1- Visual comparison } \\
\text { strategy }\end{array}$ & $\begin{array}{l}\text { Present text without reading; display } \\
\text { the word in the screen; suggest help }\end{array}$ & $\begin{array}{l}\text { The specific interface of the instrument Text: } \\
\mathrm{T} \text {; Target Word, number of the target word, } \\
\text { leanrer's statute of the word to be known; } \\
\text { Help (reading text proposed or imposed); } \\
\text { number of trying. }\end{array}$ \\
\hline $\begin{array}{l}\text { St2- using contextual } \\
\text { indices strategy (spatio- } \\
\text { semantic localization) }\end{array}$ & $\begin{array}{l}\text { Present text without reading; give set } \\
\text { of words which have the same order } \\
\text { appeared in the text; suggest help }\end{array}$ & $\begin{array}{l}\text { The specific interface of the instrument, } \\
\text { Text : T ; set of ordered target Word, number } \\
\text { of the target words, learner's statute of the } \\
\text { word to be known; Help (reading text } \\
\text { proposed or imposed); number of trying. }\end{array}$ \\
\hline $\begin{array}{l}\text { St3- partial graphical } \\
\text { location strategy } \\
\text { (locate initial capital letter) }\end{array}$ & $\begin{array}{l}\text { Present text without reading ; the learner } \\
\text { identify words which start by capital } \\
\text { letter and don't situated in the beginning } \\
\text { of the sentence, suggest help }\end{array}$ & $\begin{array}{l}\text { The specific interface of the instrument Text: } \\
\mathrm{T} \text {; set of target Word starting by capital } \\
\text { letters, number of the target word, learner's } \\
\text { statute of the word to be known; Help } \\
\text { (reading text proposed or imposed); number } \\
\text { of trying. }\end{array}$ \\
\hline $\begin{array}{l}\text { St4- using location initial } \\
\text { syllables } \\
\text { (locate initial syllables) }\end{array}$ & $\begin{array}{l}\text { Present text without reading; the learner } \\
\text { identify words which start by the same } \\
\text { syllable, suggest help }\end{array}$ & $\begin{array}{l}\text { The specific interface of the instrument Text: } \\
\mathrm{T} \text {; set of target Word starting by the same } \\
\text { syllable, number of the target words, } \\
\text { learner's statute of the word to be known; } \\
\text { Help (reading text proposed or imposed); } \\
\text { number of trying. }\end{array}$ \\
\hline
\end{tabular}


knowledge object model contains variables which are specified in the pedagogical model. The agent formulates a set of request to instantiate all the elements associated to the text for example: Find in the student model text with statute which is related to the learner's familiarization level with the text (the number of times where the text has been used by the learner, the number of sentences and words which have been used before by the learner).

The main decision variables are related to the preferences elements by the learner either teaching or learning strategies (Table1). The aim of this specification is to give an effective manner for personalizing these components taking into account the complex dynamism of the learning activity (Section 5).

\section{Conclusion and Perspective}

Research challenges for managing the complexity of future E-learning systems are not in the development or use of any one type of model. Instead, research is urgently needed in the multimodeling area. All components of the systems and solutions rely on multiple models for their design and operation. Successful complexity management, however, requires that all modelling activities be viewed within a multi formalism perspective. Some of the important research issues that stand in the way of practical multimodeling for complex systems have not been satisfactorily solved even for unitary models. The challenge posed by these issues cannot be underestimated, but there are hopeful signs, most notably the difficulty of the domain related to the individualizing learning. In fact, the history of progress in technology is also the history of progress in active multimodels. The earliest model-based decision systems incorporated unitary models; today's systems are able to control aircraft, refineries, paper mills, commercial buildings, and innumerable other engineering systems by employing several models [9]. For that we found that the design of the learning activity needs to be more focused on different fields.

Acknowledgments. Thanks to Alexandros Karatzoglou for proofreading this paper.

\section{References}

1. Barbe, W., Swassing, R.H., Milone, M.: Teaching through modality strengths: concepts and practices. Zaner-Bloser, Columbus, Ohio (1979)

2. Brusilovsky, P., Pesin, L.: ISiS-Tutor: An adaptive hypertext learning environment. In: Ueono, H., Stefanuk, V. (eds.) Proceedings of JCKBSE 1994, Japanese-CIS Symposium on knowledge-based software engineering. EIC, Tokyo (1994)

3. Cleder, C.: Planification didactique et construction de l'objectif d'une session de travail individualisée: modélisation des connaissances et du raisonnement mis en jeu. $\mathrm{PhD}$ Thesis, University Clermont-Ferrand II (December 2002)

4. Del Soldato, T., Du Boulay, B.: Implementation of motivational tactics in tutoring systems. Journal of Artificial Intelligence in Education 6(4), 337-378 (1995)

5. Dunn, R., Dunn, K., Garry, E.: Identifying individual learning styles., Student learning styles: diagnosing and prescribing programs, vol. 3, pp. 39-54. National Asssociation of Secondary School Principals (NASSP), Reston (1993) 
6. Fry, Bernard, E., Kress, J.E., Fountoukidis, D.L.: The Reading Teacher's Book of Lists, 3rd edn. Prentice Hall, Englewood Cliffs (1993)

7. John-Steiner, V., Mahn, H.: Sociocultural approaches to learning and development: A Vygotskian framework. Educational Psychologist 31, 191-206 (1996)

8. Merrill, D.: Knowledge objects and mental models. In: Wiley, D. (ed.) The Instructional Use of Learning Objects (2000), http: / / id2 . usu . edu / Papers / KOMM. PDF

9. Murray-Smith, R., Johansen, T.A. (eds.): Multiple model approaches to modelling and control. Taylor \& Francis Ltd., London (1997)

10. Paquette, G.: Instructional engineering for learning objects repositories networks. In: 2nd International Conference on Computer Aided Learning in Engineering Education, Grenoble, France, pp. 25-36 (February 2004)

11. Rabardel, P.: Les hommes et les technologies. In: Approche cognitive des instruments contemporains, Paris, Armand Colin (1995)

12. Murray, R.C., Van Lehn, K., Mostow, J.: Looking Ahead to Select Tutorial Actions: A Decision-Theoretic Approach. International Journal of Artificial Intelligence in Education (2004)

13. Säljö, R.: Mental and physical artifacts in cognitive practices. In: Reimann, P., Spada, H. (eds.) Learning in humans and machines. Towards an interdisciplinary learning science, pp. 83-96. Pergamon, London (1996)

14. Vygotsky, L.: Mind in Society: The Development of Higher Psychological Processes Cole, M. In: John-Steiner, V., Scribner, S., Souberman, E. (eds.), Harvard University Press, Cambridge (1978)

15. Wiley, D.: Connecting Learning Objects to Instructional Design Theory: A Definition, a Metaphor, and a Taxonomy. In: Wiley, D.A. (ed.) The Instructional Use of Learning Objects, pp. 3-23. AITAEC \& Technology, Bloomington, Indiana (2002) 